\title{
Water and Water Vapor Sorption Studies in Poly(propylene)-Zeolite Composites
}

\author{
H. Pehlivan, F. Özmihçi, F. Tihminlioğlu, D. Balköse, S. Ülkü \\ Chemical Engineering Department, Izmir Institute of Technology, Gülbahce Urla, Izmir, Turkey
}

Received 24 July 2002; accepted 8 January 2003

Published online 5 August 2003 in Wiley InterScience (www.interscience.wiley.com). DOI 10.1002/app.12572

\begin{abstract}
Water and water vapor sorption to porous poly(propylene)zeolite composites prepared by hot pressing have been studied as a function of zeolite loading. This work presents the first report on the effect of the zeolite as a filler on the water sorption properties of PP composites. Water swelling experiments were conducted at $25^{\circ} \mathrm{C}$ using pure $\mathrm{PP}$ and PP-zeolite film samples having different zeolite loadings (6-40 wt \%). Since PP is a hydrophobic polymer, it does not sorp any water, but the composites having 10, 20,30, and $40 \%$ zeolite sorbed $0.63,1.00,1.72$ and 3.74 wt \% water, respectively. The zeolite itself at the same conditions sorbed $24.5 \mathrm{wt} \%$ water. As the filler loading in the composites increased, equilibrium uptake values increased too. On the other hand, water vapor sorption and kinetics has been
\end{abstract}

studied using a Cahn 2000 gravimetric sorption system. Within in the range $0.35-0.95 \%$, water vapor was adsorbed by the composites containing 10-40 wt \% zeolite. Experimental effective water vapor diffusivities of the composite films were about one order of magnitude higher than the experimental water diffusion coefficient in composites. The transport of water in composites was slower than that in the liquid water due to the longer diffusion pathway and adsorption on the surface of the composites. Although the liquid water may fill all the voids in the composite, water vapor is adsorbed on the surface of the zeolite only. (C) 2003 Wiley Periodicals, Inc. J Appl Polym Sci 90: 352-359, 2003

Key words: zeolite; poly(propylene); composites

\section{INTRODUCTION}

Poly(propylene) (PP) is among the most widely exploited thermoplastic polymers and is of increasing practical importance because of its good comprehensive use, low cost, and ease of processing and recycling. It has various applications, such as the packaging, protective coating, automobile, electrical and furniture industries. However, the applications are limited by some drawbacks. To produce tailor made properties for special applications, an appropriate filler is added into the polymer matrix. The addition of fillers to the polymer is a fast and cheap method of modifying the properties of the base polymer. Among the mineral fillers for PP, mica, calcium carbonate, talc are the most often used. ${ }^{1-6}$ Each filler brings its own characteristic to the matrix and, as a consequence, to the properties of the composite. Recently, zeolites have also been employed as particulate fillers into the polymer matrix. ${ }^{7-8}$ Since the zeolite is hydrophilic and PP is hydrophobic the addition of zeolite into the PP matrix changes the water and water vapor sorption properties of PP and makes PP into a water and water vapor sorbing material. In this case, PP-zeolite composite can be used where a dessicating packaging material is needed.

Correspondence to: F. Tihminlioğlu (fundatihminlioglu@iyte. edu.tr).

Journal of Applied Polymer Science, Vol. 90, 352-359 (2003)

(C) 2003 Wiley Periodicals, Inc.
In many of the applications of PP and its composites, the material is exposed to water and atmospheric moisture for a long time. This can lead to the loss of adhesive strength by weakening the product at the interface. This damage results from the diffusion of water molecules throughout the polymer chains, causing plasticization, chain rupture and chemical degradation. Therefore the knowledge of water and water vapor sorption in composites and in polymer matrices is recognized to be of utmost importance.

Various techniques exist to measure the sorption equilibrium and kinetics data in polymer systems. Of these, gravimetric methods are the most frequently used. They rely on bulk equilibrium and hence are more time consuming, but on the other hand the technique is very accurate and reliable. The Cahn Electromicrobalance technique, which is a gravimetric one, can be used to obtain these data, and has been used by many researchers to measure water vapor sorption isotherms. $^{9-11}$ There have also been many studies on polymer composite systems. Ulutan and Balköse ${ }^{10}$ have studied water and water vapor sorption on PVCsilica membranes using a Cahn Gravimetric sorption system. Water vapor solubility, diffusivity, and permeability into membranes have been measured and found to be $4.23-7.74 \mathrm{~cm}^{3} /\left(\mathrm{cm}^{3} \mathrm{~cm} . \mathrm{Hg}\right), 2.0-3.5$ $\times 10^{-13}\left(\mathrm{~m}^{2} / \mathrm{s}\right)$, and $1.6-7.3 \times 10^{-6}\left(\left(\mathrm{~cm}^{2} / \mathrm{s}\right) /\left(\mathrm{cm}^{2}\right.\right.$ $\mathrm{cm} . \mathrm{Hg})) \mathrm{cm}$ of water vapor, respectively. Case II transport has been observed during adsorption, which was attributed to the plasticization effect of water.

Since the composite materials are exposed to water and humidity in their daily use, the attack of water 
and water vapor at the interface weaken the product. Therefore it is necessary to improve the interface by using coupling agents. Ulutan and her coworkers ${ }^{12}$ investigated the enhancement of the PVC-silica composite interface using $\gamma$-aminopropyltrimethoxysilane on silica and its effect on the liquid water and water vapor sorption. Silane application resulted in diminishing liquid water and water vapor sorption by about $24 \%$ and $12 \%$, respectively.

The sorption and transport of water in nylon 6,6 films as a function of relative humidity and temperature have been studied by Lim et al. ${ }^{13}$ They studied the moisture sorption kinetics gravimetrically using Cahn Microbalances at three different temperatures. Water vapor transmission rates were enhanced above the intermediate relative humidity $(\mathrm{RH})$ due to changes related to the glass transition. Measurements showed that water acted as an effective plasticizer in lowering Tg. Recent studies have also been conducted on the water vapor sorption of polyimides ${ }^{14-15}$ and sulfonated polyimide membranes, which have excellent applications for the microelectronic industry and proton exhange membranes for fuel cells, respectively. ${ }^{16-17}$

Metayer and coworkers ${ }^{18}$ have determined the diffusion coefficient of water in five different pure polymer films (LLPE, PET, PI, PES, unsaturated polyester resin) based on permeation measurements. By testing various polymers, different behaviors with respect to different polymers have been observed, particularly with low density polyethylene, which shows significant hydrophobic properties. Shtanko and et al. ${ }^{19}$ studied water permeability of the modified PP membranes by radiation induced graft polymerization of thermosensitive poly- $\mathrm{N}$-isopropylacrylamide. They controlled pore structure by monitoring the temperature change.

Although an extensive amount of work has been done on the water sorption of many pure polymers and polymeric composite systems, not much information is available about water or water vapor sorption in pure polypropylene and its composites. Özmihçi and coworkers ${ }^{20}$ published the only study of the permeability of PP-zeolite composite film but at low zeolite loadings (up to 6\% zeolite). Therefore, in this work, water and water vapor sorption of PP-zeolite composites has been studied as a function of zeolite loading $(6-40 \%)$. This work presents the first report on the effect of the zeolite as a filler on the water sorption properties of PP composites.

\section{EXPERIMENTAL}

\section{Material}

PP in powder form with a particle size range of 2.63$100 \mu \mathrm{m}$, from Aldrich and zeolite from Clinoptilolite, Turkey, with a particle size of $2 \mu \mathrm{m}$ were used in the composite preparation. Polyethyleneglycol (PEG
4000), was supplied by Aldrich and used for the surface treatment of the zeolite. In the modification of the zeolites, zeolites were treated with a $50 \%$ alcohol solution having 10\% PEG 4000 and at a zeolite/solution ratio of $1: 0.3$ on a weight/volume basis. The mixture was kneeded at $40^{\circ} \mathrm{C}$ and then dried in a vacuum oven at $110^{\circ} \mathrm{C}$ under a 400 mbar pressure for $3 \mathrm{~h}$.

\section{Preparation of PP composites}

$\mathrm{PP}$ and zeolite compounds were compression molded by a dry sintering process at $200^{\circ} \mathrm{C}$ and 100 bar pressure. The composites were prepared at five different zeolite loadings, 6, 10, 20, 30 and $40 \mathrm{wt} \%$.

\section{Characterization of composites}

The densities of the composites were meaured by Archimedes' principle with a Sartorious YDK01 balance. The weight of the sample and the weight of the water displaced by the sample were measured.

Electron micrographs of the gold plated fracture surfaces of the composites were taken with a Jeol Scanning electron microscope.

\section{Liquid water sorption studies}

Water swelling experiments were conducted at $25^{\circ} \mathrm{C}$ using pure PP and PP-zeolite films having different zeolite loadings (6-40 wt \%). The weights of the samples were recorded by periodically removing them from the swelling media, blotting them with absorbent tissue and weighing them. The experiments were conducted until the samples reached an equilibrium uptake. The water uptakes were plotted as a function of time. Two different runs were conducted for each sample. The results are given as the average of the two runs.

\section{Water vapor adsorption studies}

A Cahn 2000 Micro-Electrobalance instrument, shown in Figure 1, was used in the gravimetric sorption experiments. The gravimetric setup consisted of a Cahn 2000 electronic microbalance, a rotary vacuum pump, an oil diffusion pump, pressure transducers, a PID temperature controlled furnace and a water bath. Samples of $80-100 \mathrm{mg}$ were used in the experiments. The samples were dried at a pressure of about $10^{-3}$ mbar and a temperature of $100^{\circ} \mathrm{C}$. Water vapor was then let into the system in doses by opening the Edwards BRV $10 \mathrm{~K}$ needle valve. The pressure and weight data were recorded during the adsorption of water vapor by the sample. Experiments were conducted until the weight of the sample no longer changed at each pressure level. Using the simultaneous pressure and weight increase data, the adsorp- 


\section{TOP VIEW}
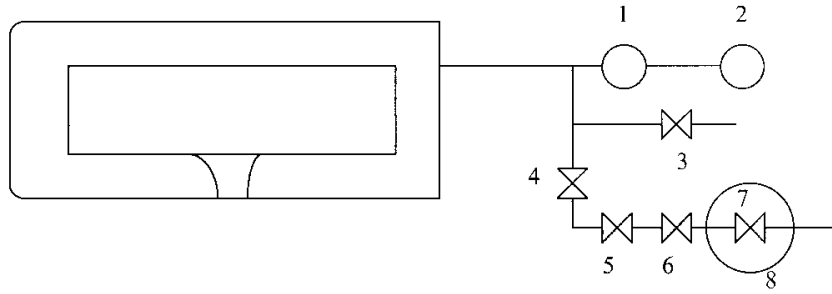

FRONT VIEW
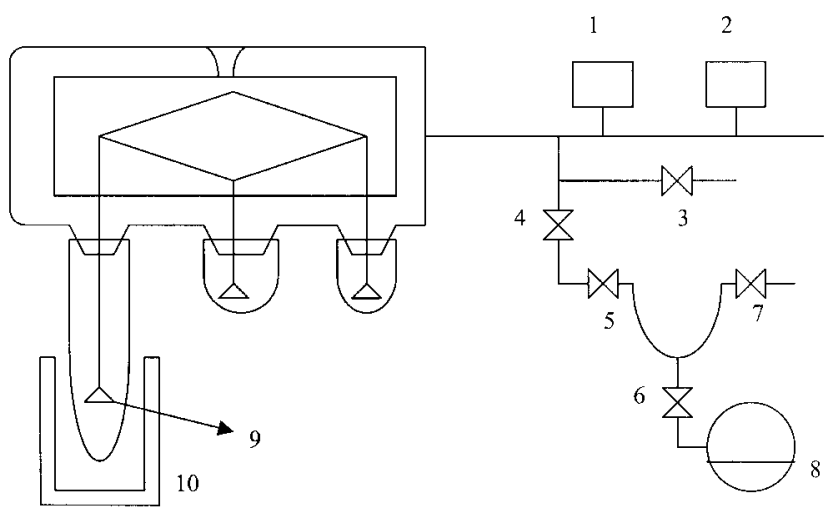

Figure 1 Cahn 2000 electro micro balance setup for water vapor sorption. Parts: $(1,2)$ Pressure Transducers; $(3,5,6,7)$ Valves; (4) Needle Valve; (8) Water vapor supply; (9) Sample; (10) Oven.

tion isotherms were obtained for the PP-zeolite composite films at $25^{\circ} \mathrm{C}$.

\section{Thermal gravimetric analysis}

For thermogravimetric studies, a Shimatzu TGA 50 apparatus was used. The samples, which were kept in liquid water for swelling experiments, were equilibrated with air of $75 \%$ relative humidity. Experiments were carried out with $10 \mathrm{mg}$ PP-zeolite films having $40 \%$ zeolite at a heating rate of 5,10 and $20^{\circ} \mathrm{C} / \mathrm{min}$ in a $\mathrm{N}_{2}$ atmosphere. The composites having $6-40 \%$ zeolite content were conditioned in the same atmosphere and then analyzed under the same conditions.

\section{RESULTS AND DISCUSSION}

\section{Characterization of porous structure of composites}

The void volume fractions of composites were found to be in the range of 0.05 to 0.16 for 10 to $40 \%$ zeolitecontaining samples by using their measured densities and eqs. (1) and (2), and the results are reported in Table I.

$$
D_{c, t}=\Sigma M_{1} / \Sigma\left(M_{1} / d_{1}\right)=\left(M_{1}+M_{2}\right) /\left(M_{1} / d_{1}+M_{2} / d_{2}\right)
$$

where $D_{c, t}$ is the theoretical density of the composite, 1 and 2 indicate zeolite and polypropylene, respec- tively, $\mathrm{d}_{1}=1.8 \mathrm{~g} / \mathrm{cm}^{3}$, and $\mathrm{d}_{2}=0.89 \mathrm{~g} / \mathrm{cm}^{3}$. Eq. (2) can be written as follows:

$$
d_{c, e}=(1-\varepsilon) d_{c, t}
$$

where $d_{c, e}$ is the experimental density of the composite and $\varepsilon$ is the void volume fraction of the composite.

The micrograph of the fracture surface of the samples in Figure 2(a) also indicates void space around zeolite particles, explaining their lower density than that predicted by eq. (1) As seen in Figure 2(a), voids grew around the particles, but void formations are not apparent in Figure 2(b) Figure 2(b) shows plastic deformation of the PP rich phase during fracture of the composites. Thus the films were not in a homogenous structure since both brittle [Fig. 2(a)] and plastic [Fig. 2(b)] fracture surfaces were present in the same sample.

\section{Liquid water sorption}

The equilibrium uptake of liquid water was investigated with respect to the amount of filler (zeolite). Figure 3 shows the water uptake of the composites containing $0-40 \mathrm{wt} \%$ zeolite. Oscillatory behavior in the water uptake of the composites was observed. It could be due to the migration of zeolite particles from the surface into the aqueous phase, causing weight loss. Since PP is a hydrophobic polymer, it does not sorp any water, but, as seen in Figure 3, the composites having 10, 20, 30 and $40 \%$ zeolite sorbed $0.63,1.00$, 1.72 and $3.74 \%$ water, respectively. The zeolite itself under the same conditions sorbed $24.5 \%$ water. As the filler loading in the composites increased, the equilibrium uptake values increased too.

Theoretical water sorption capacities of the composites were calculated using eq. (3), taking into account the additivity of matrix and filler phases on the sorption capacity. ${ }^{10,21}$

$$
X=X_{1} W_{1}+X_{2} W_{2}
$$

where $X$ is the sorption capacity of the composite (\% water $\mathrm{g} / \mathrm{g}), W$ is the weight fraction, and 1 and 2

TABLE I

Comparison of Experimental and Theoretical Densities of PP-Zeolite Composites as a Function of Zeolite Loading

\begin{tabular}{cccc}
\hline $\begin{array}{c}\text { Zeolite Loading, } \\
\%\end{array}$ & $\begin{array}{c}\text { Predicted } \\
\text { Density } \\
\left(\mathrm{g} / \mathrm{cm}^{3}\right)\end{array}$ & $\begin{array}{c}\text { Experimental } \\
\text { Density } \\
\left(\mathrm{g} / \mathrm{cm}^{3}\right)\end{array}$ & $\begin{array}{c}\text { Void Volume } \\
\text { Fraction }\end{array}$ \\
\hline 0 & 0.89 & 0.9 & 0 \\
10 & 0.98 & 0.93 & 0.05 \\
20 & 1.1 & 0.97 & 0.11 \\
30 & 1.2 & 1.03 & 0.15 \\
40 & 1.3 & 1.01 & 0.16 \\
\hline
\end{tabular}




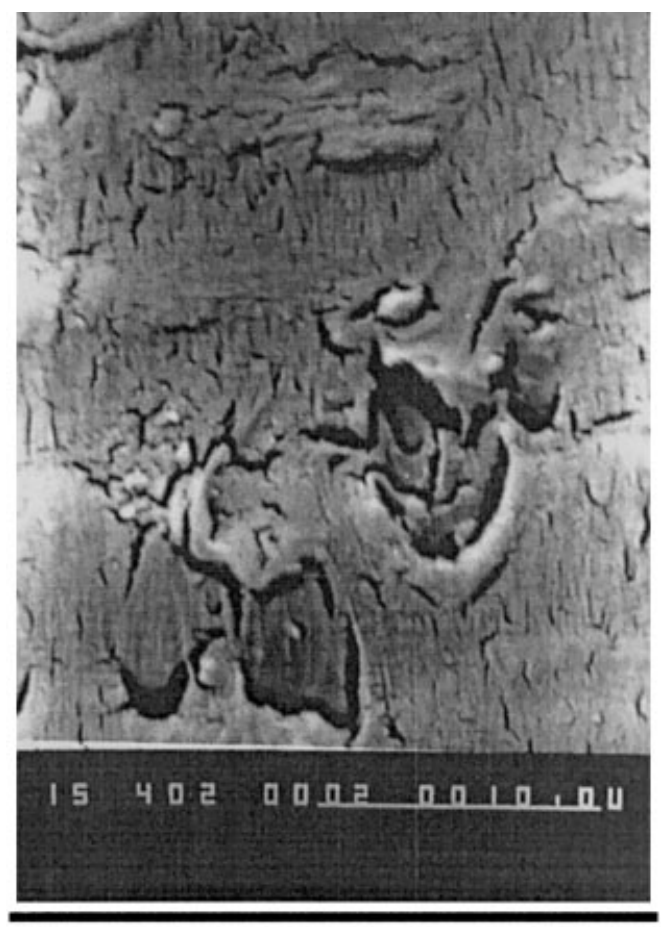

(a)

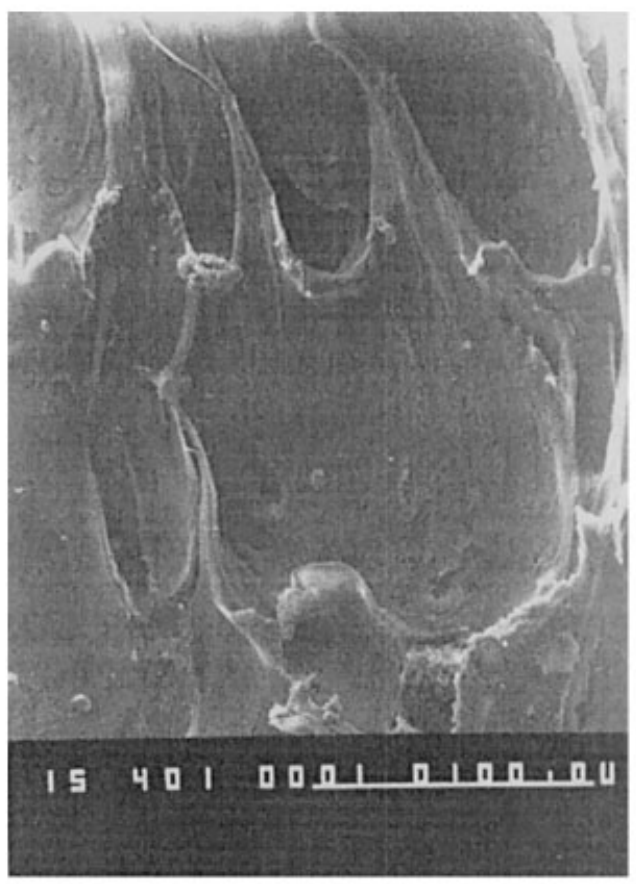

(b)

Figure 2 Scanning elecron micrograph of the PP-zeolite composites: (a) 4000× magnified composite film, (b) $400 \times$ magnified composite film.

represent the matrix and filler phases, respectively. Table II shows the experimental and theoretical water sorption capacity of the composites. As seen in Table II, if 10, 20, 30 and $40 \mathrm{wt} \%$ zeolite in the composites were fully saturated with water, they would sorp 2.45, $4.9,7.35$ and 9.8 wt \% liquid water, respectively. The experimental sorption capacity of zeolites in composites was lower than the theoretical one. This is due to the fact that water does not reach the zeolite phases easily because of the PP matrix phase and the void space around the particles were not connected to each other. This prevented water sorption of zeolites to full capacity.

Sorption process can be modelled to determine the concentration in the sample as a function of time and position using one a dimensional diffusion equation. ${ }^{22}$ For the short times, the solutions can be approximated as:

$$
\frac{M_{t}}{M_{\infty}}=\frac{4}{l} \sqrt{\left(\frac{D t}{\pi}\right)}
$$

where $M_{t}$ and $M_{\infty}$ are defined as the weight pick-ups at time $t$ and infinity and 1 are the thickness of the polymer film samples or the length of the transport path, $D$ is the effective diffusion coefficient and $t$ is the time.

By constructing a sorption curve, $\left(M_{\mathrm{t}} M_{\infty}\right.$ vs. $\left.t\right)$, the effective diffusion coefficient can be calculated from the initial slope $R_{\mathrm{j}}$, and the final equilibrium state of the curve using the following relation:

$$
D=\frac{\pi}{16} R_{i}^{2} l^{2}
$$

The average effective water diffusivities of the PPzeolite composite films for two different runs are given in Table II. As seen from the results in Table II, diffusivity values of the composites increases with the increase of zeolite loading in the composites except for the $40 \%$ zeolite loaded composites. This can be due to the nonhomogenous distribution of the zeolite in the

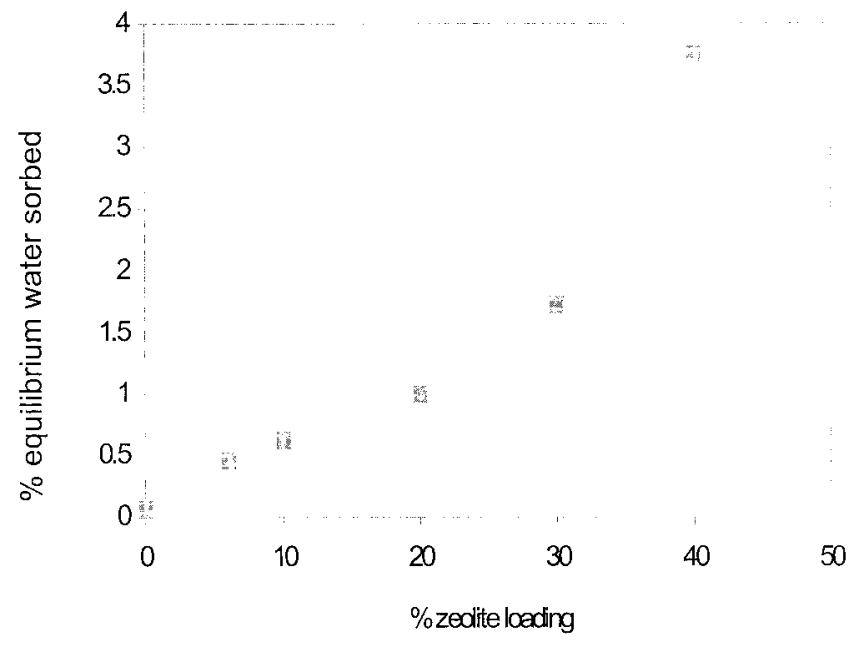

Figure 3 Water uptake of the composites containing 0-40 wt \% zeolite. 
TABLE II

Water and Water Vapor Uptake and Diffusion Results

\begin{tabular}{cccccc}
\hline $\begin{array}{c}\text { Zeolite } \\
\text { Loading, \% }\end{array}$ & $\begin{array}{c}\text { Experimental Equilibrium } \\
\text { Water Uptake, wt \% }\end{array}$ & $\begin{array}{c}\text { Theoretical Equilibrium } \\
\text { Water Uptake, wt \% }\end{array}$ & $\begin{array}{c}\mathrm{D}_{\mathrm{c}} \times 10^{10} \\
\text { Liquid Water } \\
\left(\mathrm{cm}^{2} / \mathrm{s}\right)\end{array}$ & $\begin{array}{c}\text { Experimental Water } \\
\text { Vapor Sorption, } \\
\text { wt \% }\end{array}$ & $\begin{array}{c}\text { Theoretical Water } \\
\text { Vapor Sorption, } \\
\text { wt } \%\end{array}$ \\
\hline 6 & 0.45 & 1.53 & 1.76 & - & - \\
10 & 0.63 & 2.50 & 6.40 & 0.35 & 1.35 \\
20 & 1.00 & 4.95 & 1.59 & 0.37 & 2.70 \\
30 & 1.72 & 7.40 & 3.60 & 0.63 & 4.05 \\
40 & 3.74 & 9.84 & 2.95 & 0.93 & 5.40 \\
\hline
\end{tabular}

composites and to void spaces around particles that are not connected to each other in the same manner in each sample.

The water sorption uptake was also analyzed by the following equation which has been derived for an infinite slab with a constant surface concentration. ${ }^{22}$

$$
\frac{M_{t}}{M_{\infty}}=1-\frac{8}{\pi^{2}} \sum_{n=0}^{\infty} \frac{1}{(2 n+1)^{2}} \exp \left[-\frac{D(2 n+1)^{2} \pi^{2} t}{l^{2}}\right]
$$

The results were compared to the experimental data, as shown in Figure 4, for the first set of the $40 \mathrm{wt}$ $\%$ zeolite containing film. The symbols in the figure show the experimental data, the lines are the analytical solution of eq. (6). Sequential increases of initial slope of $M_{t} / M_{\infty}$ with respect to the amount of zeolite were observed and plotted in Figure 5. The higher the amount of zeolite in the composites, the higher the slope of the water uptake and the higher the diffusion coefficient of water in the composites. Again, the symbols are the experimental data and the lines are the analytical solutions.

\section{Water vapor sorption}

The sorption isotherms of water vapor on PP composites containing 10-40 wt \% zeolite were measured.

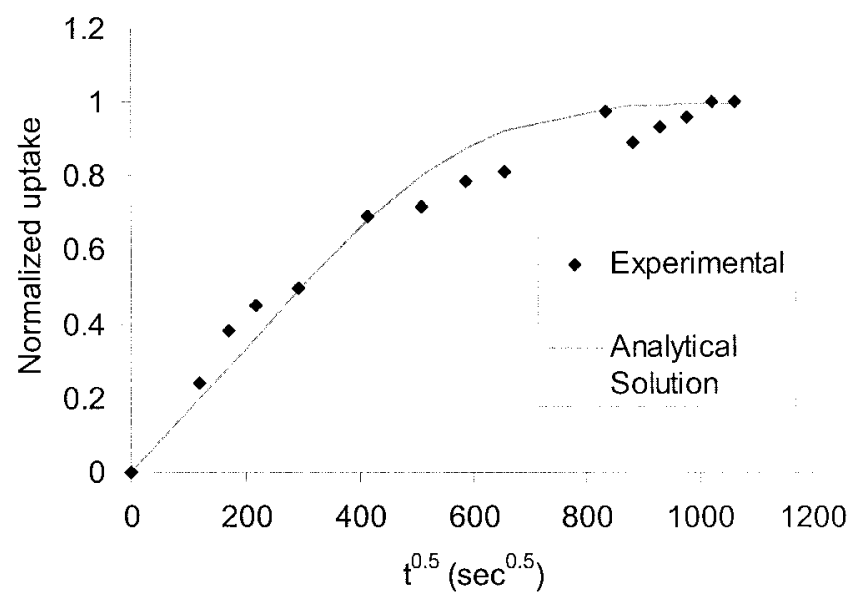

Figure 4 Comparison of the experimental and theoretical water uptake of the composites containing $40 \mathrm{wt} \%$ zeolite.
Figure 6 illustrates the sorption isotherms of water vapor in composites as percent water in composites versus relative pressure $\left(\mathrm{P} / \mathrm{P}_{\mathrm{o}}\right)$. As seen in Figure 6, the experimental isotherm of the highest zeolite loaded (40 wt \%) PP composite film gives the maximum sorption capacity. The experimental data indicate that the higher the amount of zeolite in the composites, the higher the sorption capacity. Although the neat PP does not sorp water, 10-40 wt \% zeolitecontaing PP at $5 \mathrm{mmHg}$ of pressure adsorbs 0.35 $0.95 \%$ water. Zeolite used in this study adsorbs $13.5 \%$ water wapor even at $0.5 \mathrm{mmHg}$ of pressure.

The lines in Figure 6 show the prediction of the experimental sorption isotherm data. The sorption isotherms for the composite films having 10 and $20 \mathrm{wt} \%$ zeolite were predicted using the Langmuir isotherm equations $(y=2.032 x /(1+2.032 x)$ for $10 \mathrm{wt} \%$ zeolite containing film); $y=1.685 x /(1+1.685 x)$ for $20 \mathrm{wt} \%$ zeolite containg film). The 30 and $40 \mathrm{wt} \%$ zeolite containing films were predicted using the Freundlich $\left(y=0.178 \mathbf{x}^{(1 / 2.72)}\right.$ and BET isotherm $(x / y(1-x)$ $=-3.11+0.072 x)$ equations, respectively. ${ }^{23}$

The equilibrium uptake of water vapor was investigated with respect to the amount of filler (zeolite). Figure 7 shows the comparison of liquid water and water vapor equilibrium uptake of the composites containing $0-40$ wt $\%$ zeolite. The theoretical water vapor sorption capacity was predicted using eq. (3). As shown in Table II, the theoretical sorption capacity of water vapor is also higher than the experimental one.

The experimental water vapor sorption uptake of $30 \%$ zeolite composites as a function of $\mathrm{M}_{\mathrm{t}} / \mathrm{M}^{\infty}$ versus $t^{1 / 2}$ is shown in Figure 8. Fickian behavior has been observed. Experimental effective water vapor diffusivities of $30 \mathrm{wt} \%$ zeolite film was found from the sorption data. The water vapor diffusivity value was found to be $2.8 \times 10^{-8} \mathrm{~cm}^{2} / \mathrm{s}$. The water vapor diffusion coefficient in the composites is about 1 order of magnitude higher than the water diffusion coefficient in the composites. The transport of water in composites is slower than that in the liquid water due to the longer diffusion pathway and adsorption on the surface of the composites. Although the liquid water may fill all the voids in the composite, water vapor is adsorbed on the surface of the zeolite only. 


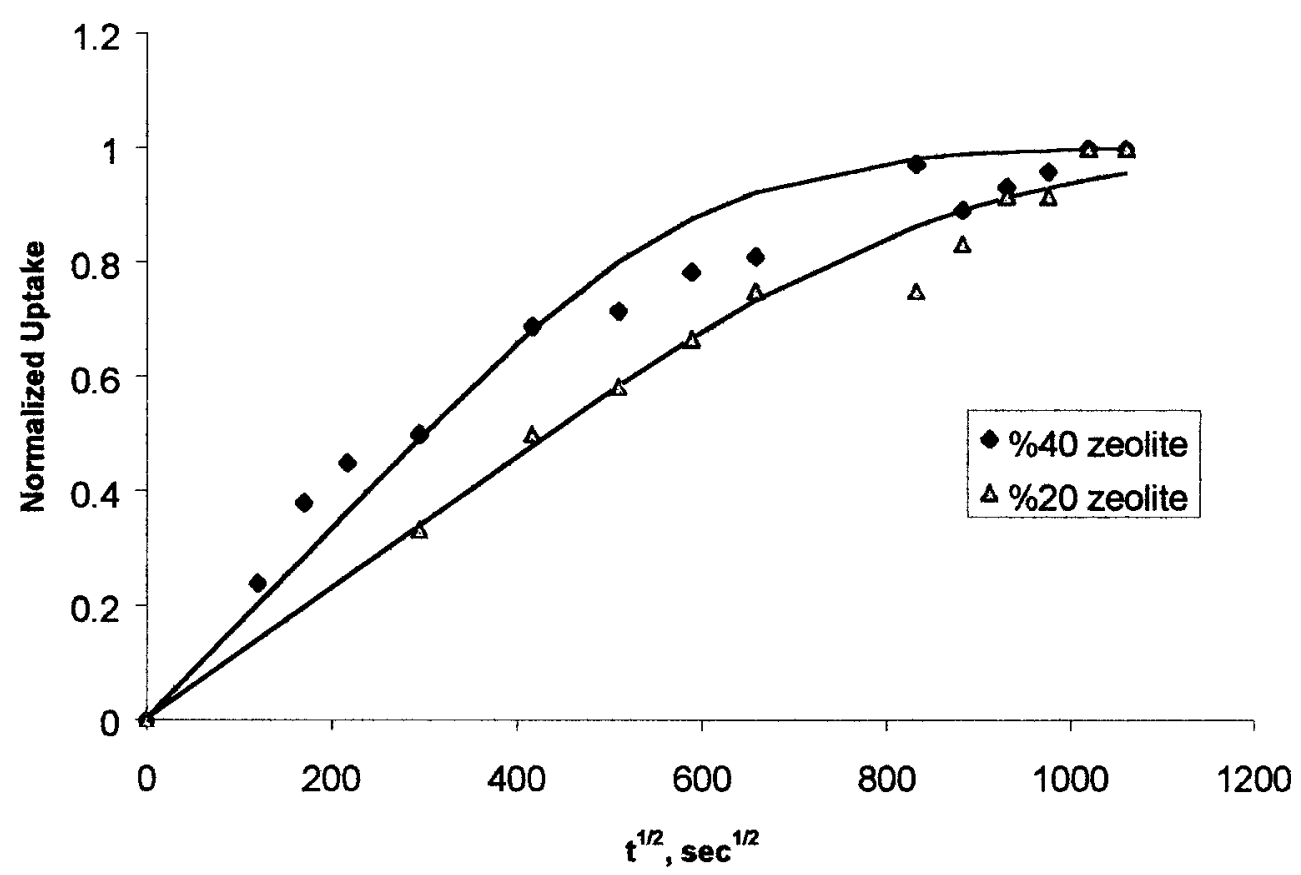

Figure 5 Comparison of the water uptake as a function of amount of zeolite into the PP matrix.

\section{Thermal gravimetric analysis (TGA)}

Figure 9 shows the TGA curve of the first experiment set of the $40 \mathrm{wt} \%$ zeolite composite film, which had the highest water uptake. This figure shows the weight loss versus temperature data at three different heating rates of 5,10 , and $15^{\circ} \mathrm{C} / \mathrm{min}$, respectively. From the TGA data, it was seen that water evaporated until it reached $150^{\circ} \mathrm{C}$, PP started to degrade thermally at $260^{\circ} \mathrm{C}$ and completed its degradation process around $450^{\circ} \mathrm{C}$. The amount of zeolite in the composite was found from weight loss data, which was collected at $600^{\circ} \mathrm{C}$. TGA showed that a $3.5 \%$ weight loss was obtained from the $40 \mathrm{wt} \%$ zeolite loaded composite film at all heating rates at $150^{\circ} \mathrm{C}$. The weight left at $600^{\circ} \mathrm{C}$ is related to the amount of zeolite in the composite films. As it was expected, the remaining weight in the composite was $40 \%$. But we observed lower values at all three heating rates. The remaining weight in the composites was found to be $20 \%, 28 \%$, and $30 \%$ at $5{ }^{\circ} \mathrm{C} / \mathrm{min}, 10^{\circ} \mathrm{C} / \mathrm{min}$, and $20^{\circ} \mathrm{C} / \mathrm{min}$, respectively. This is because of the nonhomogenous distribution of

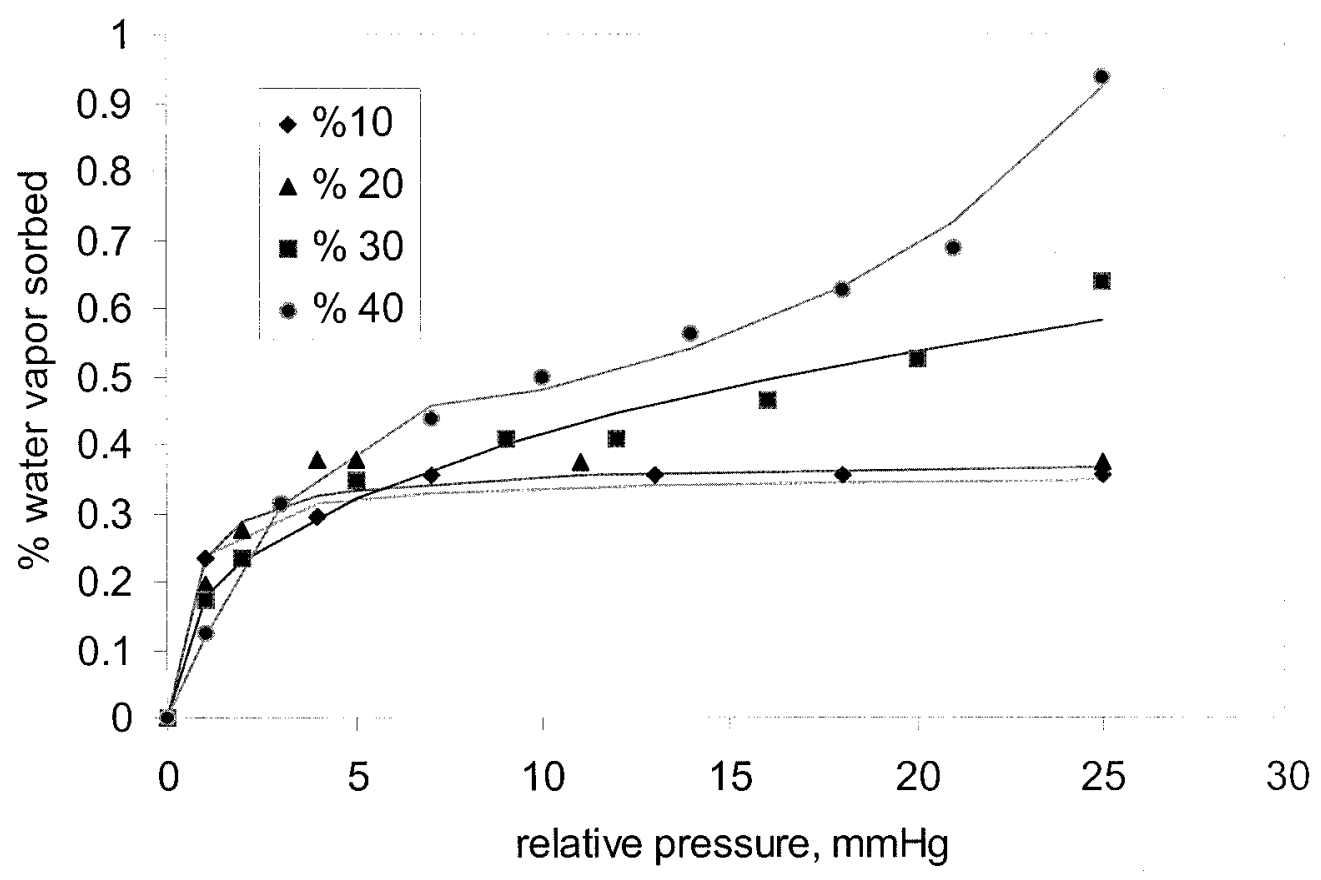

Figure 6 Sorption isotherms of water vapor in composites, as percent water in composites versus relative pressure $\left(\mathrm{P} / \mathrm{P}_{\mathrm{o}}\right)$. 


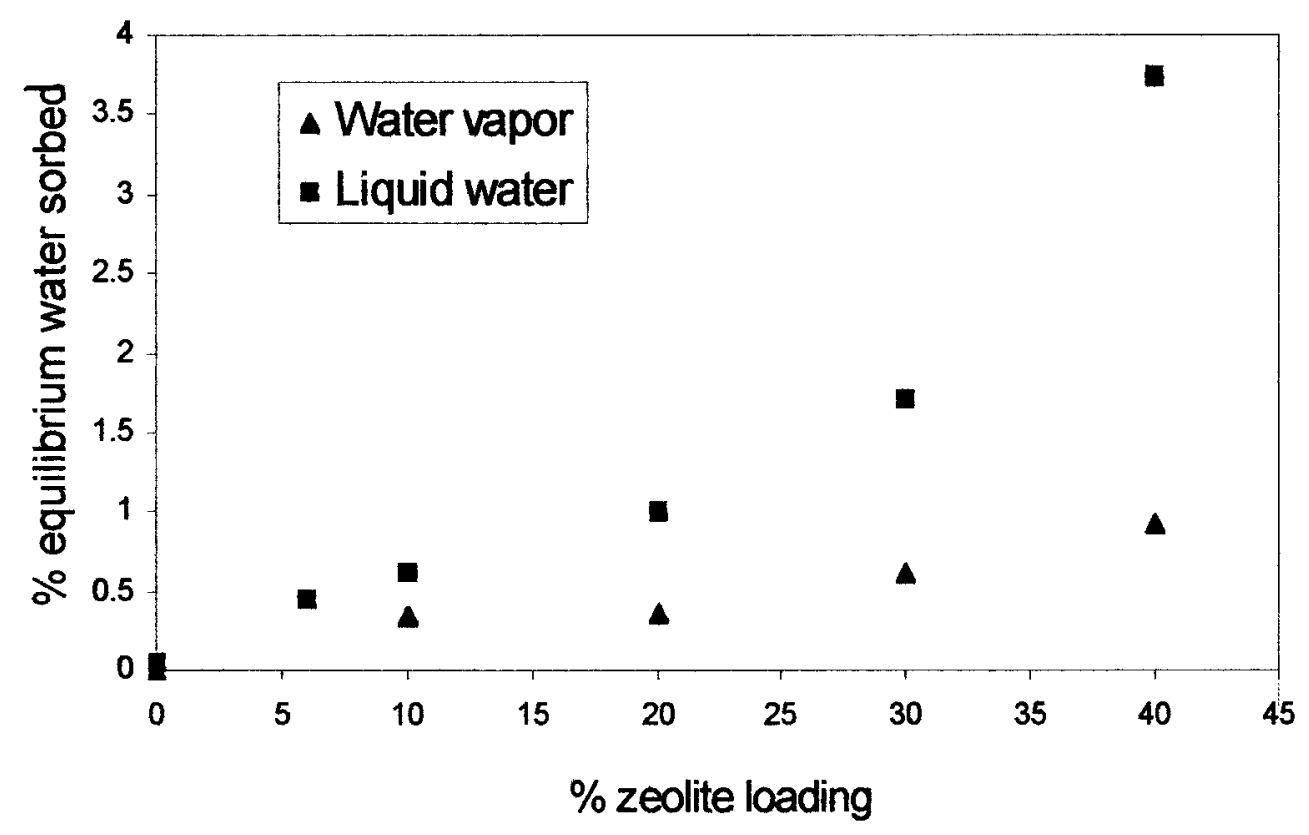

Figure 7 Comparison of liquid water and water vapor equilibrium uptake of the composites containing $0-40$ wt $\%$ zeolite.

zeolite through the PP phase achieved using the compression molding (hot press) method. The difference in particle size of PP $(2.65-100 \mu \mathrm{m})$ and zeolite $(2 \mu \mathrm{m})$, the agglomeration tendency of zeolite and the difference in density between the two also caused uneven distribution of zeolite and empty spaces between zeolites in the composites.

\section{CONCLUSION}

In this work, water and water vapor sorption and transport in PP-zeolite composite films have been in- vestigated as a function of filler amount. Since the zeolite is hydrophilic and PP is hydrophobic, the addition of zeolite into the PP matrix changes the water and water vapor sorption properties of PP and makes $\mathrm{PP}$ behave as a water and water vapor sorbing material. In this case, PP-zeolite composites can be used where a dessicating packaging material is needed.

It was observed that the equilibrium uptake values for both water and water vapor with respect to the amount of filler (zeolite) were increased as the amount of zeolite was increased. PP, a hydrophobic polymer, does not sorp any water in its pure state;

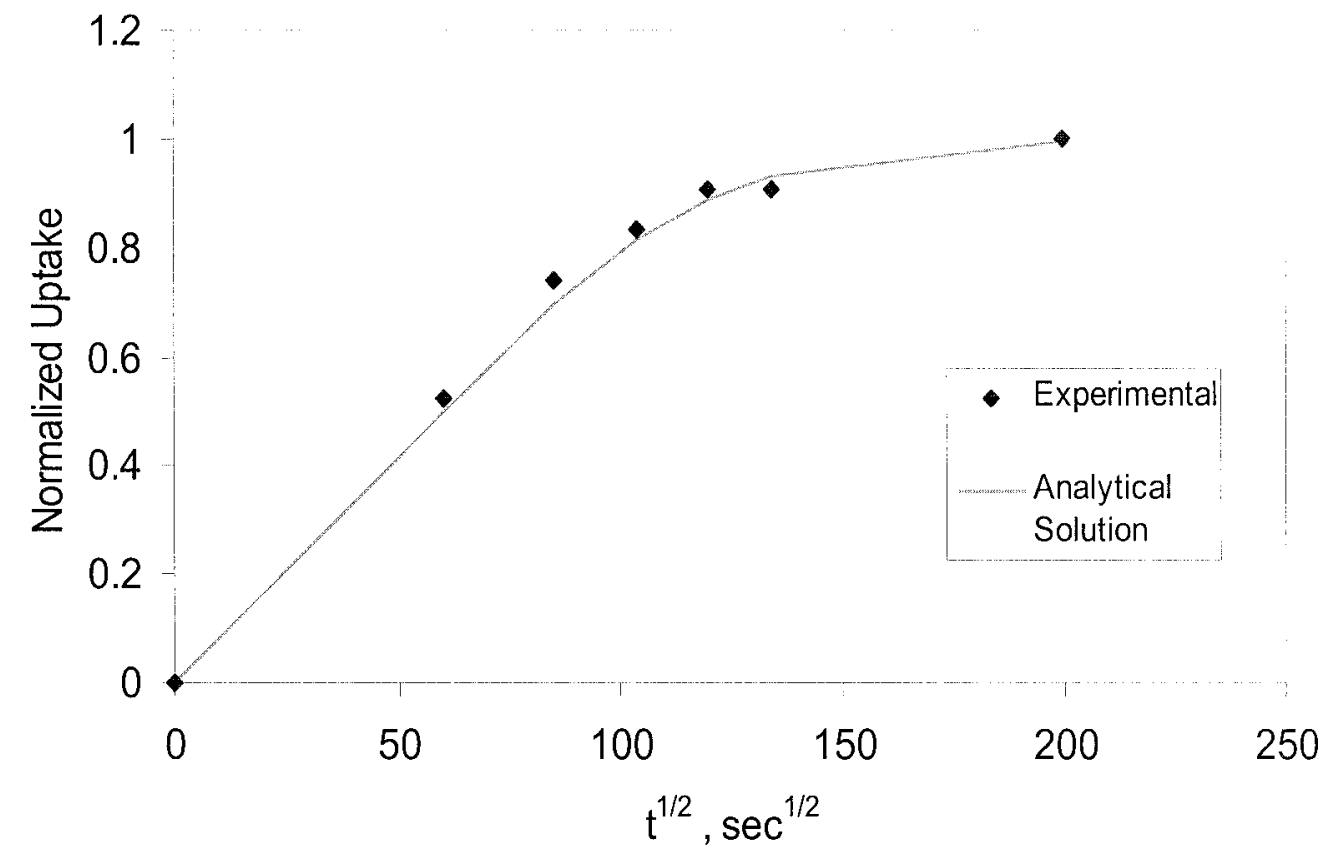

Figure 8 Experimental water vapor sorption uptake of the $30 \%$ zeolite composite as a function of $\mathrm{M}_{\mathrm{t}} / \mathrm{M}_{\infty} \mathrm{vs}^{1 / 2}$ 


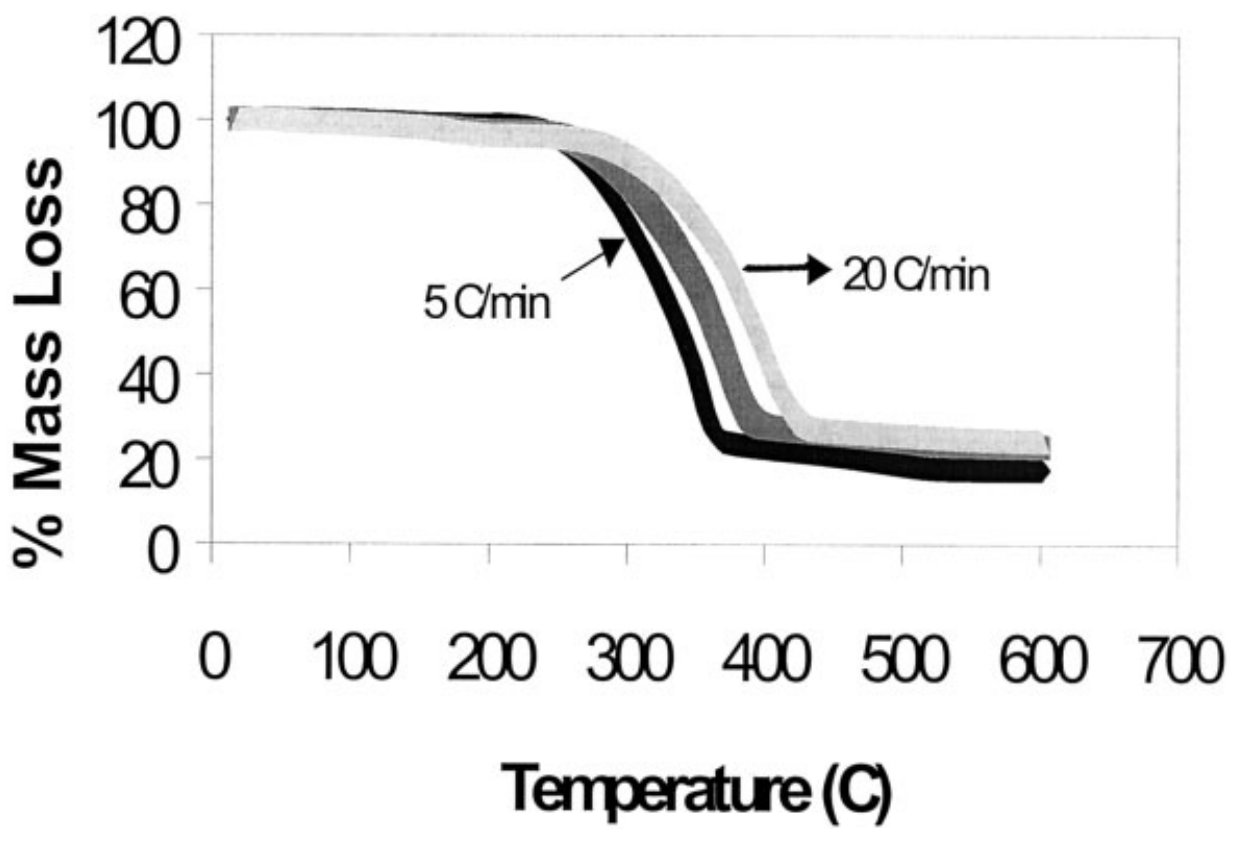

Figure 9 TGA curves of the $40 \mathrm{wt} \%$ zeolite composite film at different heating rates.

however, the composites having 6, 10, 20, 30 and 40 wt $\%$ zeolite sorbed $0.45,0.63,1.00,1.72$, and $3.74 \%$ liquid water, respectively. The zeolite used in this study by itself under the same conditions sorbed $24.5 \%$ liquid water.

As the filler loading in the composites increased, the equilibrium uptake values increased too. For water vapor sorption, the composites having 6-40 wt \% zeolite sorbed $0.35-0.95$ wt \% water vapor. It was found that the water vapor diffusion coefficient in the composites was about 1 order of magnitude higher than the water diffusion coefficient in the composites. The transport of water in the composites was slower than that in the liquid water due to the longer diffusion pathway and adsorption on the surface of the composites. Although the liquid water may fill all the voids in the composite, water vapor is adsorbed on the surface of the zeolite only. If more efficient mixing of zeolite and PP could be achieved, the composites would have a better distribution of fillers and void spaces around fillers.

The authors express their thanks to Prof. Uğur Köktürk for the scanning electron micrographic study. This research was funded by TÜBITAK grant number MISAG 129.

\section{References}

1. Stamhuis, J. E. Polym Comp 1988, 9, 72-77.

2. Tjong, S. C.; Li, R. K. Y.; Cheung, T. Polym Eng Sci 1997, 37, $166-172$.

3. Levita, G.; Marchetti, A.; Lazzeri, A. Polym Comp 1989, 10:1.
4. Galeski, A.; Kryszewski, M.; Kowalewski, T. Polym Eng Sci 1992, 32:17.

5. Nago, S.; Mizutani, Y. J App Polym Sci 1996, 61, 31-35.

6. Svelva, V.; Poloucek, E. Die Angewandte Makromolekulare Chemie 1994, 91-99.

7. Acosta, J. L.; Morales, E.; Ojeda, M. C.; Linares, A. J Mat Sci 1986, 21, 725-728.

8. Özmihçi, F.; Balköse, D.; Ülkü, S. J App Polym Sci 2001, 82, 2913-2921.

9. Balköse, D.; Ulutan, S.; Özkan, F.; Celebi, S.; Ülkü, S. App Sur Sci 1998.

10. Ulutan, S.; Balköse, D. J Mem Sci 1996, 115, 271-224.

11. Ülkü, S.; Balköse, D.; Eağa, T.; Özkan, F.; Ulutan, S. Adsorption 1998, 4, 63-73.

12. Ulutan, S.; Balköse, D. Comp Interfaces 1997, 4:4, 223-237.

13. Lim, L.; Britt, I. J.; Tung, M. A. J App Polym Sci 1999, 71, 197-206.

14. Han, H.; Seo, J.; Ree, M.; Pyo, S. M.; Gryte, C. C. Polymer 1998, 39:13, 2963-2972.

15. Han, H.; Chung, H.; Gryte, C. C.; Shin, T. J.; Ree, M. Polymer 1999, 40, 2681-2685.

16. Cornet, N.; Beaudoing, G.; Gebel, G. Sep and Pur Tech 2001, 22-23, 681-687.

17. Detallente, V.; Langevin, D.; Chappey, C.; Metayer, M.; Mercier, R.; Pineri, M. J Mem Sci 2001, 190, 227-241.

18. Metayer, M.; Labbe, M.; Marais, S.; Langevin, D.; Chappey, C.; Dreux, F.; Brainville, M.; Belliard, P. Polym Testing 1999, 18, 533-549.

19. Shtanko, N. I.; Kabanov, V. Y.; Apel, P. Y.; Yoshida, M.; Vilenskii, A. I. J Mem Sci 2000, 179, 155-161.

20. Ozmihçi, F.; Balköse, D.; Ülkü, S. J App Polym Sci 2001, 82, 2913-2921.

21. Marshall, R. A. J Vinyl Tech 1990, 12, 195-197.

22. Crank, J. Mathematics of Diffusion, $2^{\text {nd }}$ ed; Clarendon Press: Oxford, 1975.

23. Gregg, S. J.; Sing, K. S. W. Adsorption, Surface Area and Porosity; Academic Press, 1982. 